\title{
Identification and characterization of novel Aspergillus fumigatus mycoviruses
}

\section{J. Zoll, P.E. Verweij, W.J.G. Melchers}

Radboud University Medical Centre, Department of Medical Microbiology, PO Box 9101, 6500 HB Nijmegen, The Netherlands

In recent years, increasing numbers of viruses infecting fungi have been identified. In this study, we used an in silico approach for the analysis of deep RNA sequencing results in order to identify and characterize putative genomic ssRNA or dsRNA molecules of mycoviruses in Aspergillus fumigatus.
Reads from transcriptome analysis of $A$. fumigatus strains were mapped against the Af293 reference genome using CLC Genomic Workbench. Unmapped reads were used for de novo assembly. Contigs were analyzed by Blastx comparison with a mycovirus protein database. Assembled viral genomes were used as template for remapping RNA sequencing reads.
Table 1: Mycovirus genomic RNA segments found in Aspergillus fumigatus strains.

\begin{tabular}{cll} 
Strain & \multicolumn{1}{c}{ mycovirus genomic RNA \# genomic } \\
1 & Aspergillus fumigatus narnavirus 3 (AfuNV3) & 1 (partial) \\
2 & Aspergillus fumigatus partitivirus 2 (AfuPV2) & 2 \\
& Aspergillus fumigatus narnavirus 3 (AfuNV3) & 1 (partial) \\
3 & Aspergillus fumigatus narnavirus 2 (AfuNV2) & 1 \\
& Aspergillus fumigatus mitovirus (AfuMV) & 1 \\
4 & Aspergillus fumigatus tetramycovirus 1 (AfuTMV1) & 1 \\
5 & Aspergillus fumigatus narnavirus 3 (AfuNV3) & 1 (partial) \\
6 & Aspergillus fumigatus partitivirus 2 (AfuPV2) & 2 \\
7 & Aspergillus fumigatus narnavirus 1 (AfuNV1) & 1 \\
8 & Aspergillus fumigatus narnavirus 2 (AfuNV2) & 1 \\
9 & & \\
10 & Aspergillus fumigatus narnavirus 3 (AfuNV3) & 1 (partial) \\
11 & Aspergillus fumigatus tetramycovirus 1 (AfuTMV1) & 4
\end{tabular}

Figure 1: Genomic organization of the novel narnaviridae Aspergillus fumigatus narnavirus 1 (AfuNV1), Aspergillus fumigatus narnavirus 2 (AfuNV2), and Aspergillus fumigatus mitovirus (AfuMV).

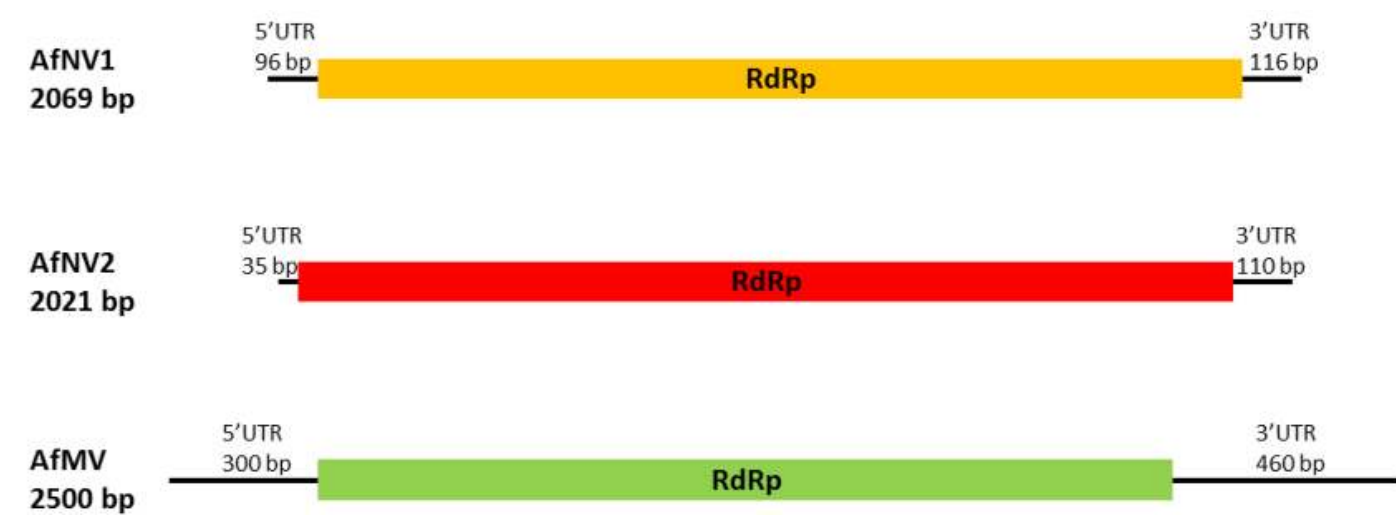

Figure 2: (A) Genomic organization of the novel Aspergillus fumigatus partitivirus 2 (AfuPV2). (B) Alignment of the 5'-UTR regions of related partitiviruses.

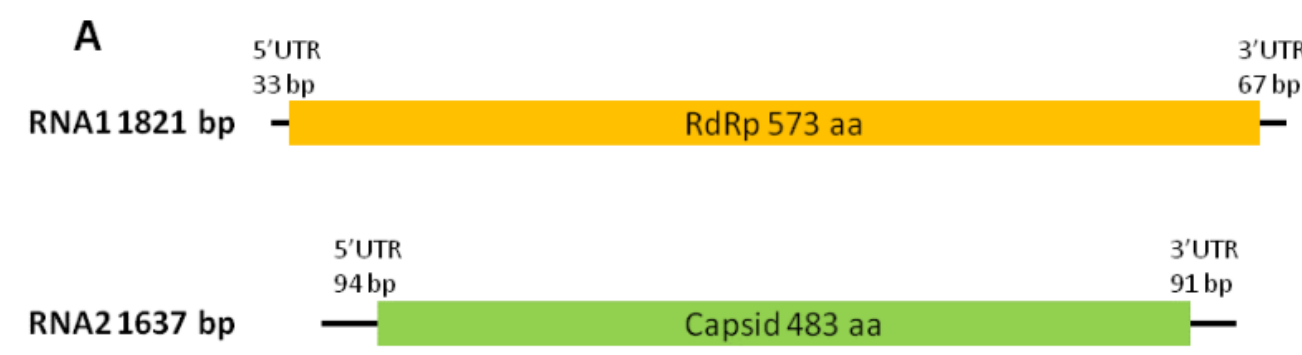

AfPV2 RNA1 CGAAAAUGAGUCACAACAUAACAGUUCCCAGCACAAUG AfPV2 RNA2 CGAAAAUGAGUCACAAUAUAACAUUUACCGGCAUUUGC BdPV1 RNA1 CGAAAAUGAGUCACAACAUUACAAUUCCCAGCACAUGC BdPV1 RNA2 CGAAAAUGAGUCACAACAUUACAUUUAUCGACACACAG AaPV1 RNA1 CGAAAAUUAGUCACAAUAUCAUAGUUCCCAGCACAUGC AaPV1 RNA2 CGAAAAUUAGUCACAAUAUUAUAUUUACCGAAUGCAAU AfPV1 RNA1 CGCAAAAGACCCUUGTCUUUUACCGCCUUGCGGGUUUUU AfPV1 RNA1 CGCAAAAGGAACCCUUUUGACUCCAGUGUAUCUGGAGG
Figure 3: Phylogenetic relationships of the family narnaviridae. The narnavirus and mitovirus genera are indicated.

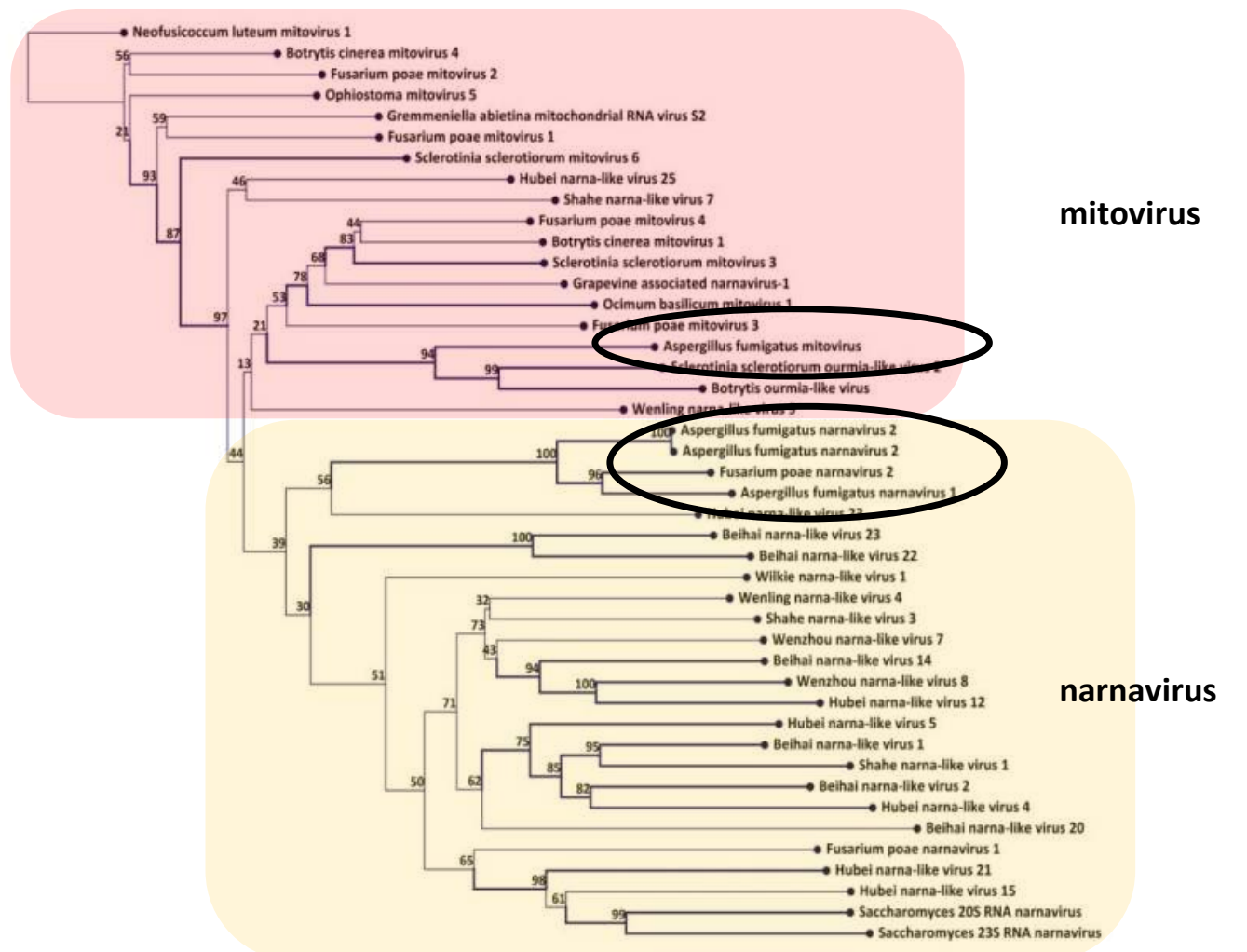

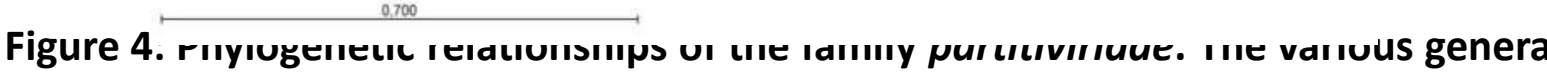
are indicated.

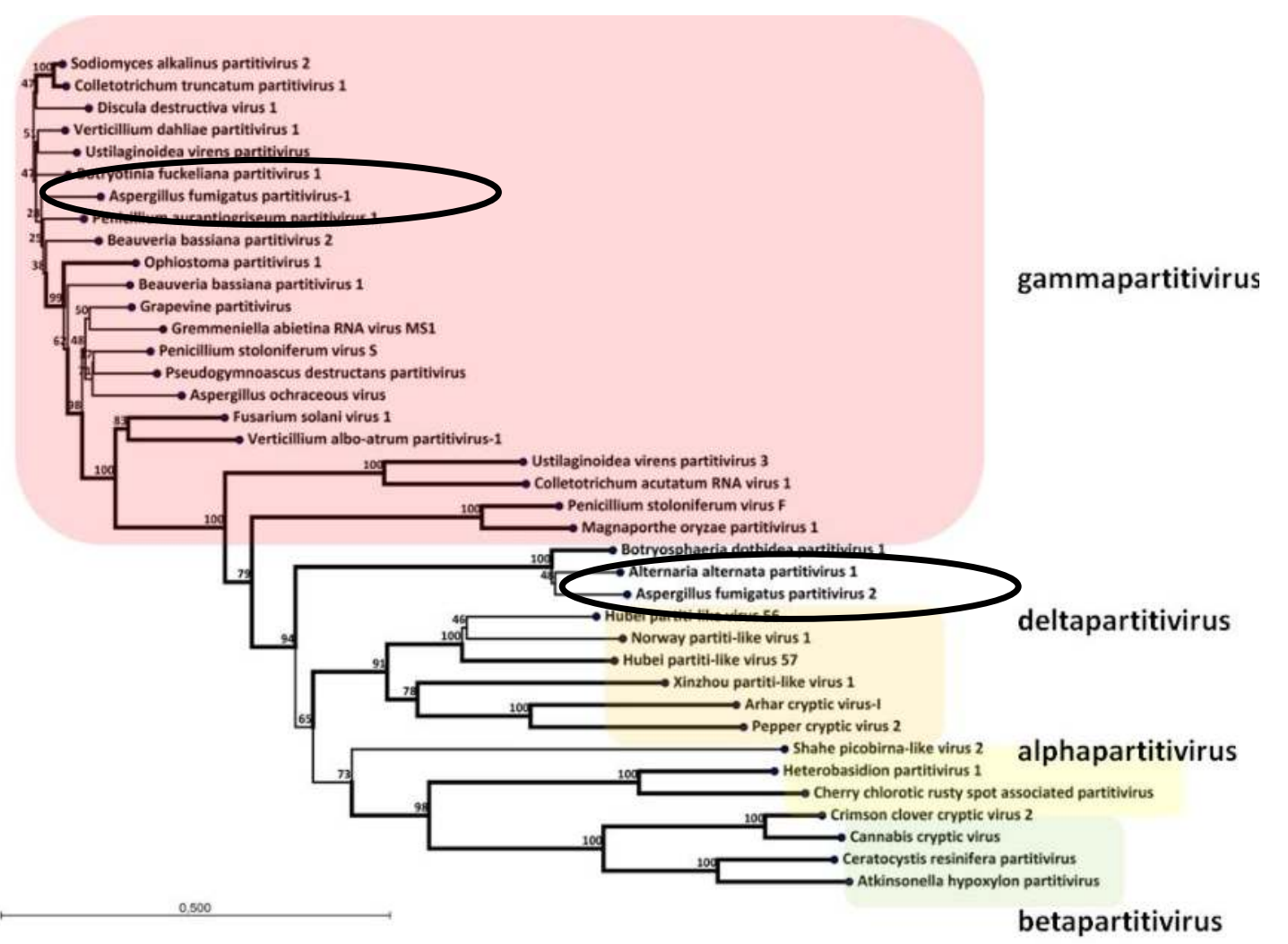

In silico analysis of deep RNA sequencing results showed that a majority of the Aspergillus fumigatus strains used in this study, were infected with mycoviruses. Four novel Aspergillus fumigatus RNA mycoviruses could be identified: Two different Aspergillus fumigatus narna-like viruses, one Aspergillus fumigatus partitivirus, and one Aspergillus fumigatus mitovirus. Further molecular and virological characterization is ongoing. 